\title{
Cidadania e democracia deliberativa na era digital - para além de Habermas ${ }^{1}$
}

\section{Citizenship And Deliberative Democracy In The Digital Age - for beyond Habermas}

\author{
Bruna Vanessa Dantas Ribeiro ${ }^{2}$ \\ (brunaribeirojor@gmail.com) \\ Ana Carolina Rocha Pessôa Temer \\ (anacarolina.temer@gmail.com) \\ Simone Antoniaci Tuzzo 4 \\ (simonetuzzo@hotmail.com)
}

\section{Resumo}

Esse trabalho trata-se de um levantamento bibliográfico das obras do filósofo e sociólogo Alemão Jürgen Habermas dentro da temática da cidadania que servem de base para uma análise de movimentos sociais e de busca da uma comunicação deliberativa no contexto do espaço público virtual e de uma possível esfera pública virtual. Utilizando como base três pilares de estudo da obra do autor: esfera pública, teoria do agir comunicativo e democracia deliberativa, busca-se resgatar a ideia de cidadania que faz parte da composição das ideias de Habermas e estabelecer uma linha de relação destas com uma atualização da esfera pública no século XXI.

Palavras-chave: Cidadania. Democracia deliberativa. Esfera pública. Agir comunicativo. Esfera pública virtual.

\section{Abstract}

This paper is related to a literature survey of the works of the German philosopher and sociologist Jürgen Habermas within the theme of citizenship that are the basis for an analysis of social movements and pursuit of deliberative communication in the context of virtual public space and a possible virtual public sphere. Using as a basis the three pillars of study the author's work: public sphere theory of communicative action and deliberative democracy, seeks to rescue the idea of

\footnotetext{
${ }^{1}$ Este trabalho foi desenvolvido dentro do Projeto de Pesquisa Rupturas Metodológicas para uma leitura crítica da Mídia entre os Programas de Pós-Graduação da UFG e UFRJ, que integra a ação transversal nº 06/2011 - Casadinho/Procad.

${ }^{2}$ Mestranda da Universidade Federal de Goiás, linha de pesquisa mídia e cidadania - Graduada em Comunicação Social, com habilitação em jornalismo pela Faculdade ALFA.

${ }^{3}$ Pós-doutora em Comunicação pela Universidade Federal do Rio de Janeiro. Doutora e mestre em Comunicação Social pela Universidade Metodista de São Paulo. Professora do Programa de Pós-Graduação da Faculdade de Comunicação e Biblioteconomia - FACOMB, da Universidade Federal de Goiás.

${ }^{4}$ Doutora em Comunicação pela UFRJ, Mestre e Graduada em Comunicação pela UMESP, Coordenadora do Projeto de Pesquisa Rupturas Metodológicas para uma leitura crítica da Mídia entre os Programas de Pós-Graduação da UFG e UFRJ, que integra a ação transversal no 06/2011 - Casadinho/Procad. Professora e Orientadora do Trabalho desenvolvido na disciplina Seminários Temáticos de Mídia e Cidadania - PPGCOM - UFG.
}

Comunicação \& Informação, v. 16, n. 1, p. 186-201, jan./jun. 2013 
citizenship as part of the composition of the ideas of Habermas and establish a line of their relation to an update public sphere in the XXI century

Keywords: Citizenship. Deliberative democracy. Public Sphere. Communicative action. Virtual public sphere.

\section{Introdução}

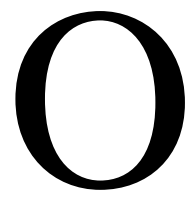

trabalho de Habermas é muito vasto, passando por teorias políticas e do direito, sociais e da comunicação, podendo ser aplicado nos mais variados temas. Tratando-se de um estudo da cidadania, ontem e hoje, dentro das ideias do autor é necessário um recorte temático preciso, partindo dessa ideia serão utilizadas de três pilares fundamentais de estudo para guiarem este trabalho e servirem de base para análise do redesenho desta esfera pública no contexto de mídias digitais e cidadania virtual: espaço público, democracia deliberativa e teoria da ação comunicativa.

\section{Esfera Pública}

Em 1962 Habermas lançou uma de suas mais repercutidas e polêmicas obras. Em Mudança Estrutural da Esfera Pública o autor trata da formação da esfera pública moderna a partir da formação da esfera pública burguesa de pessoas privadas reunidas e formando um público. Essa esfera pública se desenvolveu de 1690 a 1870, inicialmente como um esfera literária que se reunia em cafés britânicos e salões franceses, em função de leituras e discussões dos recém criados jornais e panfletos noticiosos, e posteriormente adquiriu um "caráter privado e polêmico, contra a autoridade do estado" (SIGNATES, 2009, p.149).

Apesar desta obra tratar da importância do surgimento da imprensa na construção da esfera pública burguesa e a evolução desta esfera através de uma construção histórica, durante toda a obra fica difusa e distribuída a definição do que é a esfera. Esse conceito vem de forma bastante clara na obra Direito e Democracia - Entre Facticidade e Validade (I e II) de 1992. Nessa obra o conceito de espaço público deixa de ser histórico normativo para se tornar uma visão sociológica (SIGNATES, 2009):

A esfera pública pode ser descrita como uma rede adequada para a comunicação de conteúdos, tomadas de posição e opinião; nela os fluxos comunicativos são filtrados e

Comunicação \& Informação, v. 16, n. 1, p. 186-201, jan./jun. 2013 
sintetizados a pontos de condensarem opiniões públicas enfeixadas em temas específicos. Do mesmo modo que o mundo da vida tomado globalmente, a esfera pública se reproduz através do agir comunicativo implicando apenas o domínio de uma linguagem natural. (HABERMAS, 2011b, p.93)

Aprofundando ainda mais: “A esfera pública constitui principalmente uma estrutura comunicacional do agir orientado pelo entendimento, a qual tem a ver com a espaço social gerado no agir comunicativo, não com as funções nem com os conteúdos da comunicação cotidiana." (HABERMAS, 2011b, p.93)

Para Habermas qualquer encontro, troca de informação, que parta da posição reciproca de comunicação alimentado pela liberdade comunicativa que uns concedem a outros, acontece em um espaço público, ou seja, a esfera de diálogo (esfera pública) existe em um espaço público. Assim como o ator, a ação, o grupo ou a coletividade, a esfera pública é também um fenômeno social elementar. Sendo assim, este é constituído através da linguagem. "Na esfera pública luta-se por influência" (Habermas, 2011b, p.96) pois, a influência se forma nela. A esta altura de seu trabalho a discussão sobre esfera pública passa a carregar um maior peso de cidadania.

Apesar de Mudança Estrutural Da Esfera Pública ser uma das obras mais marcantes de Habermas e seu conceito de esfera pública servir como base para grande parte dos estudos sobre a opinião pública, e sua formação, que o sucederam, além de chave para se entender e estruturar as ideias subsequentes do autor, ela é também uma obra constantemente criticada, em grande parte por seu recorte histórico social: A leitura e discussão sobre os periódicos feita nos espaços públicos dos cafés e salões. Dois exemplos dessa visão são John Thompson e Peter Burke.

Para o historiador Peter Burke, Habermas apenas faz uma tradução para a linguagem do século XX de ideias defendidas no século XVIII, por pensadores domo Diderot e Voltaire, e ainda sim peca pela simplicidade. Burke aponta a falha de Habermas em não considerar reuniões e formações de opinião pública anteriores ao século XVIII, em contar com a possibilidade de não existência da esfera pública dentro de determinadas sociedades e de negligenciar a importância da mulher dentro da construção da esfera pública burguesa. "Pode ainda ser verdade quando se diz que as mulheres muçulmanas participem menos das questões públicas do que os homens muçulmanos ou mulheres ocidentais, mas isso não é a mesma coisa que dizer que elas não participam em nada dessas questões" (BURKE, 2002). Ao citar o exemplo Árabe, Burke demonstra que é ainda possível se analisar o organismo da esfera pública através uma visão menos eurocêntrica e ocidentalizada. 
Na obra Mídia e Modernidade Thompson (2008) faz uma análise da Mudança estrutural que vai além das questões históricas apontadas por Burke. Para Thompson as falhas de Habermas podem ser divididas em seis pontos chave: 1) Habermas negligencia outros discursos e atividades públicas não burguesas instituídas nos séculos XVII, XVIII e XIX. 2) A definição dos periódicos fundamentais na mudança da esfera pública burguesa foi em grande parte delimitada pela própria crítica de Habermas, assim os periódicos serviram aos seus propósitos, pode-se contar que ele se baseou em periódicos que não eram os primeiros e nem os mais comuns da época. 3) Baseou-se em uma burguesia idealizada, que não necessariamente refletia a realidade da época. A real excluía pobres, analfabetos e mulheres. 4) Habermas faz uma análise errônea do declínio da Burguesia ao afirmar que a volta da publicidade representativa assemelhava-se a estrutura de opinião pública dos feudos, ocorrendo assim uma "refeudalização" da sociedade. 5) Habermas foge à realidade ao apostar demasiadamente na comunicação dialógica face-a-face, que difere da comunicação e ação comuns no mundo moderno.

Apesar de todas as críticas não há nenhuma obra subsequente do autor que trate de trazer para o século XXI as ideias construídas em Mudança estrutural da esfera pública, Habermas somente volta a comentar sobre suas possíveis falhas na construção histórica e social de sua teoria da formação da esfera pública burguesa no prefácio da $17^{\circ}$ edição alemã do livro, lançada em 1990. Habermas faz um estudo e levantamento das criticas recebidas, assumindo seu descaso com alguns movimentos históricos sociais e classes da sociedade civil. Neste texto atualizado ele admite ter sido negligente quanto a alguns movimentos sociais subculturais que ele considerou como segundo plano das ações de mudança estrutural que se davam fundamentalmente na esfera burguesa. É Marcante neste prefácio a mudança quanto a visão do autor sobre a participação feminina na construção da esfera pública. Habermas se reposiciona ao admitir que a não participação das mulheres nas discussões nos cafés e salões é em si uma característica da estruturação da sociedade civil burguesa:

Diferentemente da institucionalização do conflito de classes as modificações da relação entre os sexos não intervêm somente no sistema econômico, mas também no núcleo privado da esfera íntima da família restrita. Desta forma se revela claramente o fato de a exclusão das mulheres ter sido um elemento constitutivo da esfera pública política, no sentido de que esta não estava somente dominada pelos homens de maneira contingente, mas determinada, na sua estrutura e sua relação com a esfera privada, segundo um critério sexual. De maneira distinta da exclusão dos homens desfavorecidos, a exclusão das mulheres representa um papel constitutivo na formação das estruturas da esfera pública. (HABERMAS, 1990, p.5)

Comunicação \& Informação, v. 16, n. 1, p. 186-201, jan./jun. 2013 
A partir desse momento é possível ver um maior interesse do autor na temática feminista, sendo citada em obras posteriores ao prefácio, como em Direito e Democracia e A Inclusão Do Outro, onde ele usa o exemplo dos movimentos feministas para realizar análises teóricas.

Apesar de todas suas críticas sobre a esfera pública Habermasiana, Burke defende que "Nós estamos com ele mesmo quando pensamos contra ele" (BURKE, 2002), deixando claro sua posição de que mesmo não concordando com muitos pontos da obra do sociólogo alemão, sua criação foi fundamental para abrir espaço para críticas e discussão da esfera pública que temos hoje, e que mais a frente será discutida sob a forma a indagações sobre uma possível esfera pública virtual.

\section{Teoria Da Ação Comunicativa}

A teoria da ação comunicativa vem como uma resposta de Habermas a teoria da racionalização de Weber, sendo assim a teoria de Weber repousa na consciência e a de Habermas na Linguagem. Nesta, que se tornou a principal obra de Habermas, fica clara a quebra do filósofo com a Escola de Frankfurt e Adorno e Horkheimer. Ao apostar na ideia de que a dominação não se exerce pela linguagem, já que todos temos o direito de dizer não, assim só há poder em operações extralinguísticas, o autor foge a negatividade frankfutiana: “A comunicação pode servir de base para a reconstrução racional dos fundamentos da vida social, superar a visão negativa dos velhos frankfurtianos e construir um novo paradigma de desenvolvimento da teoria da sociedade" (RÜDINGER, 1998, p.94 apud TEMER; NERY, 2004, p.96).

Os dois volumes de Teoria do agir comunicativo (1981) se tornaram a mais importante obra de Habermas, funcionando assim como uma condensação do cerne ideológico de suas obras. A ação comunicativa seria uma solução a invasão da racionalidade burocrática e econômica do sistema que penetra no "mundo da vida", que pode ser definida como uma "ação voltada para o entendimento" (RÜDINGER, 1998, p.94 apud TEMER; NERY, 2004, p.96) estruturada por uma racionalidade comunicativa, que é a maneira como os indivíduos comunicantes empregam saber, resultado em uma comunidade ideal de comunicação onde a igualdade e liberdade são alcançadas. "A razão comunicativa, portanto, é uma forma de interação social em que os planos de ação dos indivíduos são coordenados pelo intercâmbio de atos comunicativos" (TEMER; NERY, 2004, p.96).

A ação comunicativa tem sua validade obtida através de quatro fatores da comunicação: Inteligibilidade, veracidade, verdade e correção. Somente através desses fatores o discurso pode ser 
validado. Dois pontos importantes para se entender a ação comunicativa são os conceitos de mundo da vida e sistema, que pode-se resumir, segundo o autor, como:

- Sistema: Economia e estado

- Mundo da vida: esfera privada e esfera pública

Para Habermas a sociedade, onde se exerce a ação comunicativa, consiste em uma união do mundo da vida com o sistema. Apesar de utilizar o conceito de sistema Luhman, em Teoria dos sistemas, Habermas vai contra a ideia defendida pelo autor de que a sociedade é em si um sistema: "Todo contato social é entendido como sistema, inclusive a sociedade enquanto conjunto da consideração de todos os contatos possíveis" (LUHMAN, 1985, p.33 apud REESE-SCHÄFER, 2009, P.55). Ao contrário dessa ideia, ele considera que só é possível compreender as patologias do mundo moderno diferenciando sistema de mundo da vida.

Ao sair da Negatividade predominante nos estudos frankfurtianos, Habermas acaba por desenvolver uma teoria social baseada na linguagem que funciona também como uma possibilidade, ou utopia, de autodeterminação da sociedade de forma a validar a cidadania. Com uma visão humanista da comunicação, acreditando que ela parte da consciência dos seres humanos envolvendo também questões de valores, ética e o discurso, Habermas se contrapõe a teoria dos sistemas de Luhman (1995), onde a comunicação só envolve o processo comunicativo e não há envolvimento da consciência dos sujeitos comunicantes.

\section{Democracia Deliberativa}

Em seus dois livros Direito e Democracia - Entre Facticidade e Validade Habermas trata da filosofia do direito, não se desviando de sua temática da comunicação como base das relações e construção social. Primeiramente ele faz uma critica aos dois modelos políticos tradicionais: capitalismo e socialismo. Para o autor o capitalismo utiliza os imperativos do dinheiro e do poder para deformar as estruturas simbólicas do mundo da vida, implantando assim uma sociedade individualista, onde falta a coletividade. É cada um por si e todos pelo dinheiro e o poder.

Já no socialismo/comunismo predomina uma invasão da esfera privada em detrimento de um coletivismo que coloca em cheque a autonomia e individualidade dos cidadãos, implicando perigo de antidemocracia. Como nos casos de ditaduras socialistas como a Coréia do Norte e Cuba. Para Habermas dentro de uma sociedade democrática não se deve cair no individualismo, porém a posição do indivíduo como parte do todo Público não pode se sobrepor a sua condição humana. 
Defendendo que os homens vem antes do povo, ele discorda do posicionamento coletivista do Jurista alemão Carl Schimitt:

\begin{abstract}
O conceito democrático da igualdade é um conceito político e faz referência à possibilidade da diferenciação. A democracia portanto não pode fundamentar-se na falta de diferenças entre todos os seres humanos, mas apenas na concernência a determinado povo...A igualdade, que faz parte da essência da democracia, dirige-se, portanto, apenas de dentro para fora. (SCHMITT, 1983, p. 227 apud HABERMAS, 2011, p.161)
\end{abstract}

Então fica uma pergunta: qual modelo político seria o ideal para a sociedade pós-moderna? Fugindo desses dois modelos o autor busca um modelo político que não se atenha ao individualismo do capitalismo, nem a falta de autonomia privada e individualidade do socialismo/ comunismo. Habermas (2011a, p.127) utiliza-se do conceito de autonomia introduzido por Kant e de modelo político de Rousseau para aprofundar-se na ideia de uma Democracia Deliberativa, fundamentada na ideia de que direitos do homem só existem dentro da autonomia política.

Nesse novo modelo político, nem de esquerda e nem de direita, a decisão substituiria a ordem e a soberania do povo através das instituições, a soberania individual de atores políticos. Sendo assim Habermas retoma a ideia do agir comunicativo, aplicando-a em um contexto de estruturação político social sob a forma de mediação comunicativa, reconhecimento mútuo do discurso de livre dominação, baseando-se assim na existência de um poder comunicativo. "O sistema político é então não mais a ponta nem o centro da sociedade, mas um sistema comunicativo de ações, entre outros" (REESE-SCHÄFER, 2009, P.177). Esse poder comunicativo seria gerido por uma ética cognitivista, que é um código de normas e valores utilizado na reflexão pública utilizada na tomada de decisões, validada pelo discurso.

Essa Sociedade dos cidadãos é formada pela tríade da sociedade burguesa (estado, mercado e sociedade civil) acrescida da solidariedade, que é possibilitada pelo poder comunicativo. Esse poder comunicativo, que é em si uma transformação da opinião pública, não pode servir de instrumento de dominação do poder administrativo, mas serve para direcioná-lo. Assim "opiniões públicas representam potenciais de influência Política" (HABERMAS, 2011b, p.96)

Toda a construção da democracia deliberativa é fundamentada nos conceitos de esfera pública, já citada, e de sociedade civil, ambos trabalhados em Direito e Democracia - Entre Facticidade e Validade II. Nesta obra Habermas define sociedade civil a partir de seu cerne constitutivo: 
O seu núcleo institucional é formado por associações e organizações livres, não estatais e não econômicas, as quais ancoram as estruturas de comunicação da esfera pública nos componentes sociais do mundo da vida. A sociedade civil compõe-se de movimentos, organizações e associações, os quais captam os ecos dos problemas sociais que ressoam nas esferas privadas, condensam-nos e os transmitem, a seguir, para a esfera política." (HABERMAS, 2011b, P.100)

A participação desta sociedade civil na formação da democracia deliberativa garante sua efetivação. Formam-se através do processo de soberania do povo, formação discursiva da opinião e da vontade pública, várias periferias sociais: esferas públicas mais acessíveis, consequentemente mais sensíveis aos problemas sociais. A sociedade civil habermasiana está apoiada nos direitos fundamentais, entre eles o direito a informação e liberdade de opinião, já que a sociedade civil é a esfera onde se pratica o poder comunicativo e à comunicação cabe o papel de regulador jurídico:

A liberdade de opinião e de reunião, bom como o direito de fundar sociedades e associações, definem o espaço para as associações livres que interferem na formação da opinião pública, tratam de temas de interesse geral, representam interesses e grupos de difícil organização, perseguem fins culturais, religiosos ou humanitários, formam comunidades bem confessionais, etc. a liberdade de imprensa, do rádio e da televisão, bem como o direito de exercer atividades publicitárias, garantem a infraestrutura medial da comunicação pública a qual deve permanecer aberta a opiniões concorrentes e representativas. (HABERMAS, 2011b, p.102)

Segundo Habermas uma sociedade civil mobilizada tem o poder de quebrar com a dominação através dos meios, pilar dos estudos de Adorno e Horkheimer, sendo esta dominação midiática possível somente em situações de esfera pública em repouso.

\section{A Esfera Pública Na Era Digital}

Para Burke, Habermas é negligente em não considerar aquilo que Mcluhan chamou de cultura eletrônica (televisão e rádio), mas não se pode dizer o mesmo da internet. Em 1962 ainda não existia nenhuma tecnologia que possibilitasse a capacidade de transferência e armazenamento de dados, e consequentemente a comunicação fluída e sem fronteiras, que temos hoje com a internet, assim não se pode considerar que a mesma negligência teria acontecido com a cultura digital. Seria impossível para Habermas prever a dimensão que a internet e a mídias digitais possuiriam e como essa nova tecnologia mudaria as estruturas sociais, políticas e econômicas da sociedade atual. 
Muito mudou no mundo pós Mudança Estrutural da esfera pública e o autor não retornou a esta obra no sentido de atualizar a análise da construção da esfera pública através das mudanças ocasionadas pelas novas mídias. Portanto coube, e ainda cabe, a outros autores tratar da esfera pública habermasiana no século XXI.

Hoje é inegável a utilização do espaço virtual como espaço público semelhante ao dos cafés a salões analisados por Habermas: espaços que possibilitam a comunicação de conteúdos, tomadas de posição e opinião, ou seja, espaços de livre ação comunicativa que abrindo oportunidade de livre expressão de vários indivíduos ou grupos gera um filtro opinativo que condensa a opinião pública em temas específicos. Mais inegável ainda é a existência de uma virtualidade cidadã, que cresceu com a internet e utiliza-se dela para se articular dentro e fora da virtualidade e se reafirmar no mundo da vida enquanto movimento de mudança.

É possível dividirmos movimentos sociais virtuais atuais em duas chaves de funcionamento: movimentos pré existentes que migraram para o âmbito virtual, assim coexistindo com os movimentos reais, utilizando-se da virtualidade para sua sobrevivência, e os novos movimentos que começam com a discussão no espaço público da internet para se estender a realidade atuando tanto em ações virtuais como físicas. Apesar dessa diferenciação de origem do discurso, ambos mostram que Pierre Levy não está errado, ou demasiadamente positivo, em defender uma coexistência da virtualidade com a realidade, não havendo anulação ou sobreposição de uma sobre a outra. "Quanto às relações 'virtuais', não substituem pura e simplesmente os encontros físicos, nem as viagens, que muitas vezes ajudam a preparar. Em geral é um erro pensar as relações entre antigos e novos dispositivos de comunicação em termos de substituição" (LEVY, 2007, p.129).

Para Levy o ciberespaço, este como "espaço de comunicação aberto pela interconexão mundial dos computadores e memória dos computadores" (LEVY, 2007, p.92), propicia a exploração de novas formas de opinião pública e é um desvio técnico para se atingir a inteligência coletiva.

Apesar da proximidade da virtualidade com a esfera pública habermasiana e da constante construção de conhecimento sobre os movimentos de busca pela cidadania e os direitos na internet duas questões fundamentais permeiam os estudos e reflexões sobre a comunicação nas novas mídias: é possível pensar em uma esfera pública virtual coexistente com a esfera pública tradicional? Como fica a relação dos movimentos sociais virtuais e da luta pelos direitos na internet com as mídias tradicionais? 
Esta resposta divide opiniões, para Levy é clara a importância do ciberespaço, enquanto espaço de desenvolvimento da inteligência coletiva, na construção de uma comunicação deliberativa "universal sem totalidade" (2007, p.111). Já para Sampaio e Barros a internet tem um inegável potencial interativo e discursivo, mas não alcança o patamar de esfera pública:

De maneira geral, constata-se que a internet não é uma esfera pública virtual por si, mas que pode ser utilizada pelos seus usuários para incrementar as discussões na esfera pública, podendo, em determinadas situações, desencadear demandas sobre o sistema político formal. (2011, p.180).

Esfera pública ou não, talvez ainda seja cedo para se definir, mas de forma alguma devemos desconsiderar a forma como esse espaço possibilita horizontalizar a produção informacional, o que propicia uma descentralização do poder sobre a informação e seu maior fluxo. É importante ainda considerar a forma como a internet é utilizada para se articular as lutas sociais e como a virtualidade modificou a forma de se discutir assuntos públicos e de se manifestar com relação a eles, porém ainda é cedo para excluir a presença das mídias e tradicionais e principalmente da esfera pública habermasiana.

Paiva (2013) trata de conceituar uma nova forma de ação das minorias como ação flutuante. Os movimentos minoritários incorporam novas tecnologias às suas ferramentas de trabalho, mas constantemente se articulam em função de aparecerem nas mídias tradicionais, o que gera um constante aparecimento/ ocultamento desses movimentos. Mesmo utilizando-se do espaço público virtual para se articular, os "movimentos flutuantes" dependem do espaço público tradicional para se validar.

\section{Um Novo Comunicar, Um Novo Manifestar-se}

Exemplos práticos do uso do espaço público virtual para a discussão de assuntos públicos gerando assim uma nova forma de se comunicar e construir os movimentos sociais pode ser visto através de uma comparação dos movimentos Occupy wall street em Nova York, Gezi na Turquia e Primavera Árabe em vários países.

O Occupy Wall Street é um movimento iniciado em setembro de 2007 que protesta contra a desigualdade econômica e social causadas pela ganância das empresas do setor financeiro norte americano que influenciam o estado. Com o Slogan "We are the 99\%" cerca de 10 mil pessoas ocuparam a Wall Street em Nova York, em um protesto que se espalhou pelos Estados Unidos. O 
movimento continua existindo e hoje seu site ${ }^{5}$ é usado para divulgar outros movimentos ao redor do mundo.

A onda democrática conhecida como Primavera Árabe se iniciou na Tunísia em 2010, com um protesto de auto imolação, e se espalhou por 17 países do Oriente Médio e norte da África, levando milhares de pessoas às ruas, causando a derrubada de chefes de estado em 3 países (Tunísia, Egito e Líbia), reformas políticas em vários países e levando a Síria a uma guerra civil. Apesar de motivos específicos diferentes, os dezessete países estavam reunidos em reclamações contra as condições de vida precárias, contra regimes ditatoriais e a falta de direitos.

O mais recente deles, o movimento Gezi, começou em Istambul como protesto pacífico que reclamava a não derrubada de 600 árvores do parque Taksim Gezi, famoso espaço público de discussões, para a reconstrução de um quartel militar do império Otomano. O movimento que começou com alguns ambientalistas se espalhou pela Turquia e tem levado milhares de pessoas às ruas. $\mathrm{O}$ que se iniciou como um protesto pontual em defesa da praça Gezi, hoje reúne várias reclamações e se tornou um reflexo da indignação a população turca com o governo e fundamentalismo político do primeiro ministro Recep Tayyip Endorgan.

Em texto publicado pela revista VICE o jornalista Brian Merchant faz uma comparação destes movimentos, e mostra que apesar de diferentes motivações e localidades esses movimentos possuem algumas semelhanças: 1) espontaneidade: apesar de um pequeno grupo iniciar o movimento seu crescimento e a adesão popular foram espontâneas, grande parte ocasionada pela internet. 2) Falta de cobertura da mídia local contornada pelo uso da internet. 3) O excesso de violência policial em resposta aos protestos que pode ser documentada pelos participantes, que usaram a internet para divulgar os movimentos e a truculência da polícia.

Os movimentos ao redor do mundo adquiriram o que Merchant chama de "anatomia própria" apesar da distância física eles acabaram por possuir características semelhantes, graças a sua forma de se comunicar e a recusa do estado em se abrir para o diálogo, de possibilitar uma maior interatividade popular:

Uma liderança pouco responsável está determinada a não abrir um diálogo significativo com os dissidentes. A pressão aumenta e a polícia fica mais brutal. A brutalidade se torna viral, assim como a indignação. Manobras ágeis nas redes sociais fornecem ferramentas adicionais para os organizadores e canais para essa indignação. (MERCHANT, 2013)

\footnotetext{
${ }^{5}$ http://occupywallst.org
} 
No caso desses movimentos a luta se desenvolveu no âmbito dos espaços públicos reais, porém foi o uso da internet como forma de articulação que deu a esses movimentos a possibilidade de um maior alcance popular e político.

Já para um estudo da validade de uma possível esfera pública virtual na busca de uma democracia deliberativa e direitos de uma forma geral, para mudança dentro das instituições é interessante analisar a atuação da Organização das Nações Unidas na internet.

É bastante visível o posicionamento da Organização Das Nações Unidas (ONU) pró política e comunicação deliberativas incentivadas e efetivados pelas novas tecnologias, e muito disso se dá através do uso das mídias digitais para se comunicar e ouvir os cidadãos do mundo. Através de várias plataformas online a organização além de comunicar suas ações, mantém também canais abertos de comunicação direta com populações de todo o mundo, dando a esses indivíduos a possibilidade de se expressar, sites de transparência com documentos sobre os mais variados temas dos direitos humanos, política e sociedade e realiza pesquisas de opinião quantitativas e qualitativas com várias populações.

Um exemplo claro da abertura comunicativa dentro da ONU com uso das novas tecnologias é o projeto Meu Mundo 2015, realizado juntamente com a Fundação World Wide Web e o Instituto de Desenvolvimento Internacional. O projeto, finalizado em março de 2013, consistia em uma pesquisa realizada com qualquer pessoa do mundo interessada em responder, a fim de definir quais seriam as prioridades das pessoas na construção de o mundo melhor, o projeto também abriu espaço para as organizações e empresas que podiam participar através dos escritórios locais. Cada pessoa ou instituição deveria escolher seis dentre 16 itens de uma lista de prioridades. Qualquer indivíduo podia participar, bastava acessar o site ${ }^{6}$ da pesquisa e os resultados alcançados seriam distribuídos com os líderes mundiais responsáveis por formular a Agenda De Desenvolvimento Global pós2015:

A ONU quer que esta nova agenda resulte de um processo realmente aberto e inclusivo, que envolva pessoas de todas as partes do mundo e de todos os grupos sociais e, por isso, está realizando uma pesquisa mundial intitulada "Meu Mundo", criada como uma ferramenta para incluir a voz de todos neste diálogo global. ${ }^{7}$

\footnotetext{
${ }^{6} \mathrm{http}: / / \mathrm{www} . \mathrm{myw}$ orld2015.org/?lang=pr

${ }^{7}$ Disponível em <http://www.onu.org.br/meumundo/>.
} 
O projeto defende não só a participação da população no desenvolvimento da agenda pós 2015, mas a transformação dessa participação em políticas públicas, como fica claro na fala da antropóloga Iara Pietrickovisk, escolhida como "voz" da sociedade civil no encontro ocorrido no Brasil que marcou o final da primeira etapa da pesquisa "Diálogo social: agenda pós-2015 e seguimento à Rio+20":

A participação é um direito humano. Estamos vivendo em uma época que os governos não conseguem sozinhos deliberar decisões que envolvem toda a população. $\mathrm{O}$ elemento de participação passa a ser crucial, mas não tem que ser como atualmente, em que se junta grupos de determinados temas em conferências, sem ter uma escuta inicial, sem devolutiva, não transformando o que foi incorporado em politica pública, orçamento e com uma avaliação se foi eficaz e efetivo. Tem que participar, mas não apenas pelo participar. ${ }^{8}$

A ONU conta hoje com uma Agência para questões de informação e tecnologias da comunicação a União Internacional de Telecomunicações (UIT) ${ }^{9}$, que trata somente de assuntos ligados a cidadania e direitos humanos relacionados às tecnologias da informação.

\section{Conclusão}

Habermas não é conclusivo quanto à cidadania, não dá um significado ou conceito fechado, mas trabalha com ela em toda sua obra. A cidadania está presente no desenvolver da teoria da ação comunicativa, na mudança estrutural da esfera pública e naquilo que ela se transformou, chegando aos dias de hoje, e principalmente em sua ideia de democracia deliberativa. Mais do que uma ideia de cidadania ativa, que segundo Soares "Institui o cidadão como portador de direitos e deveres, mas essencialmente participante da esfera pública e criador de novos direitos para abrir espaços de participação", (2004, p.46) Habermas propõe uma reformulação estrutural do modelo político no qual o indivíduo comunicativo passa a ser parte constitutiva do poder público, fazendo parte de sua estrutura através do poder comunicativo, da sua capacidade de pensar e discutir problemas publicamente.

Levando-se em conta os avanços tecnológicos ocorridos na segunda metade do século XX e início do século XXI é impossível se falar em uma reformulação estrutural da sociedade e da efetivação de uma democracia deliberativa e uma maior busca da cidadania sem falar da internet.

\footnotetext{
${ }^{8}$ Disponível em: http://www.unfpa.org.br/novo/index.php/noticias/entrevistas/545-participacao-da-sociedade-civil-e-fundamentalpara-garantir-a-agenda-pos-2015

${ }^{9}$ Site da organização: 〈http://www.itu.int/en/Pages/default.aspx>.
} 
Tanto as ações virtuais da ONU em prol de organizar uma comunicação deliberativa, quanto os movimentos sociais citados ainda são falhos no sentido de se construir democracias deliberativas por estas ainda estarem suscetíveis a aceitação e manobras dos poderes hegemônicos.

É impossível negar que estas sejam ações que buscam a comunicação deliberativa, a participação do povo nas decisões políticas e, portanto, são um ensaio da soberania popular através do agir comunicativo, mas estão ainda em estágio muito primário. Esses movimentos só podem crescer e alcançar maior alcance quando os estados tiverem suas estruturas de funcionamento modificadas de forma a incluir definitivamente o diálogo aberto do povo e de fazer entender que o povo tem poder através da comunicação na esfera pública, como acredita Habermas.

Mais do que somente fazer uma análise jurídica, política e social da problemática moderna, através da ideia de democracia deliberativa (que pode se obter com uma sociedade dos cidadãos, formada por uma opinião pública pensante e uma sociedade civil atuante) Habermas também sugere uma solução, mesmo que utópica. Possível ou não de ser efetivada, a política deliberativa serve como parâmetro comparativo para avaliar os poderes públicos vigentes na pós-modernidade e acender a ideia de que a validação dos direitos do homem, fundamentais e universais, só é possível através da autonomia política dos cidadãos, ou seja, da soberania do povo.

Artigo submetido em 20/09/2013 e aceito em 01/10/2013.

\section{Referências}

BURKE, Peter. A esfera pública 40 anos depois. Disponível em: <http://www1.folha.uol.com.br/fsp/mais/fs2403200207.htm>. Acesso em: 09 jun. 2013.

HABERMAS, Jürgen. A inclusão do outro: estudos de teoria política. São Paulo: Loyola, 2002.

HABERMAS, Jürgen. Espaço público 30 anos depois. Disponível em:

<https://docs.google.com/file/d/0bvwcdyckp5smguzyjq3ndmtytrizc00zjbllwfmzdutyzjmngq1n2qy mgew/edit>. Acesso em: 02 jun. 2013.

HABERMAS, Jürgen. Direito e democracia: entre facticidade e validade I . Rio de Janeiro: Tempo Brasileiro, 2011.

HABERMAS, Jürgen. Direito e democracia: entre facticidade e validade II . Rio de Janeiro: Tempo Brasileiro, 2011.

HABERMAS, Jürgen. Mudança estrutural da esfera pública: investigações quanto a uma categoria da sociedade burguesa. Rio de Janeiro: Edições Tempo Brasileiro, 2003. 
HABERMAS, Jürgen. Teoria do agir comunicativo: sobre a crítica da razão funcionalista I . São Paulo: Wmf Martins Fontes, 2012.

HABERMAS, Jürgen. Teoria do agir comunicativo: sobre a crítica da razão funcionalista II . São Paulo: Wmf Martins Fontes, 2012.

LEVY, Pierre. Cibercultura. São Paulo: Editora 34, 2007.

LEVY, Pierre. A esfera pública no século XXI. Disponível em:

$<$ http://techyredes.files.wordpress.com/2011/08/techyredes_artigo-pierre-levy1.pdf $>$. Acesso em: 17 jun. 2013.

LUHMANN, Niklas. Social systems. Stanford: Stanford University Press, 1995.

MCLUHAN, Marshall. A galáxia de Gutenberg; a formação do homem tipográfico. São Paulo: Editora Nacional, Editora da USP, 1972.

MERCHANT, Brian. Da Tahrir ao Occupy a Istambul: uma anatomia dos protestos atuais e futuros. Revista Vice, 08 jun. 2013. Disponível em: <http://www.vice.com/pt_br/read/da-tahrir-ao-occupya-istambul-uma-anatomia-dos-protestos-atuais-e-futuros>. Acesso em: 08 jun. 2013.

MEU MUNDO 2015. Disponível em: <http://www.onu.org.br/meumundo/>. Acesso em 19 jun. 2013.

PAIVA, Raquel. Política de minorias: comunidade e cidadania. Disponível em:

<http://www.labcom.ubi.pt/files/agoranet/03/paiva-raquel-politica-de-minorias.pdf >. Acesso em: 19 jun. 2013.

PARTICIPAÇÃO da sociedade civil é fundamental para garantir agenda pós-2015, diz antropóloga. Disponível em: <http://www.onu.org.br/participacao-da-sociedade-civil-e-fundamental-paragarantir-agenda-pos-2015-diz-antropologa/>. Acesso em: 25 maio 2013.

REESE-SCHÄFER, Walter. Compreender Habermas. Petrópolis: Editora Vozes, 2009.

SAMPAIO, Rafael C.; BARROS, Chalini T. G. Internet como esfera pública? Análise de usos e repercussões reais das discussões virtuais. Revista Estudos em Comunicação: Covilhã, n. 9, p. 161-183, maio 2011.

SIGNATES, Luiz. A sombra e o avesso da luz: Habermas e a comunicação social. Goiânia: Editora Kelps, 2009

SOARES, Maria Vitoria Benevides. Cidadania e direitos humanos. In CARVALHO, José Sérgio. Educação, cidadania e direitos humanos. Petrópolis: Vozes, 2004. 
TEMER, Ana Carolina Rocha Pessoa; NERY, Vanda Cunha Albieri. Para entender as teorias da comunicação. Uberlândia: EDFU, 2012.

THOMPSON, John B. A mídia e a modernidade: uma teoria social da mídia. Petrópolis: Vozes, 2008. 